\title{
Development of a Gravure Printed Flexible Electrochemical Sensor
}

\author{
D. Maddipatla*, B. B. Narakathu, V. S. Turkani, B. J. Bazuin, M. Z. Atashbar \\ Department of Electrical and Computer Engineering, \\ Western Michigan University, Kalamazoo, MI, USA \\ *dinesh.maddipatla@wmich.edu
}

\begin{abstract}
:
A flexible electrochemical sensor was successfully fabricated using additive gravure printing process for the detection of biochemicals. The sensor, with a circular electrode configuration, was printed on a flexible polyethylene terephthalate (PET) substrate using silver nano-particle (Ag-NP) ink. The capability of the electrochemical sensor was investigated by performing electrical impedance spectroscopy (EIS) measurements towards different concentrations of potassium chloride $(\mathrm{KCl})$ solution, at $20 \mathrm{~Hz}$ operating frequency and $100 \mathrm{mV}$ excitation voltage. It was observed that the impedance decreased from $1329 \mathrm{k} \Omega$ to $207 \mathrm{k} \Omega$ to $183 \mathrm{k} \Omega$ to $68 \mathrm{k} \Omega$ to $1.2 \mathrm{k} \Omega$ as the concentration of the $\mathrm{KCl}$ solution increased from DI to $100 \mathrm{pM}$ to $100 \mathrm{nM}$ to $100 \mu \mathrm{M}$ to $100 \mathrm{mM}$, respectively, thus demonstrating picomolar (pM) concentration detection capability of the printed sensor.
\end{abstract}

Key words: Additive Manufacturing, Electrochemical Sensor, Gravure Printing, Flexible PET substrate, Silver Nano Particle Ink.

\section{Introduction}

Over the last decade, there has been a considerable effort focused on the development of disposable and cost effective electrochemical sensors for the detection of biochemicals in the agricultural, medical, environmental and biomedical industries [1]. Typically, electrochemical sensors are fabricated on rigid substrates by employing lithography based processes which involves complex deposition techniques and time consuming processes, thus making them relatively expensive [2]. Therefore, the development of simple, costefficient, and portable electrochemical sensors on flexible platforms, is important. This has led to the research of using additive printing processes for the fabrication of flexible electrochemical sensors.

Printed electronics (PE), which uses additive manufacturing processes such as inkjet, screen, gravure, and flexography printing, is an emerging area which has the potential to advance the field of sensors. These printing processes allow roll-to-roll (R2R) fabrication at low operating temperatures with high throughput and offers many advantages such as cost efficiency, reduced wastage of materials and less complex manufacturing steps. PE has enabled fabrication of many flexible electronic devices such as RFID tags, organic thin film transistors, strain sensors, pressure sensors, and electrochemical sensors for applications in the biomedical, automotive, environmental and defense industries [3-5]. There are many reports available on the fabrication of electrochemical sensors using screen and inkjet processes. However, there are few reports on the fabrication of flexible electrochemical sensors using gravure printing process.

\section{Experimental}

A schematic of the circular electrode configuration based electrochemical sensor with a working electrode (1700 $\mu \mathrm{m}$ radius) and a circular electrode (inner and outer radius of $2900 \mu \mathrm{m}$ and $3900 \mu \mathrm{m}$ ) is shown in Fig. 1(a). A flexible and transparent polyethylene terephthalate (PET) film (DuPont Melinex ${ }^{\circledR}$ ST 506) of $127 \mu \mathrm{m}$ thickness was employed as a substrate. A conductive silver nano-particle (AgNP) ink (TEC-PR-020) with an average particle size of 20-50 nm from Inktec Inc. was used as a metallization layer. The two Ag-NP electrodes were deposited on the PET substrate using a laboratory scale K-Printing Proofer gravure press from Testing Machines Inc ((Fig. 1(b)). The electrical impedance spectroscopy (EIS) measurements of the printed sensor towards different concentrations of potassium chloride 


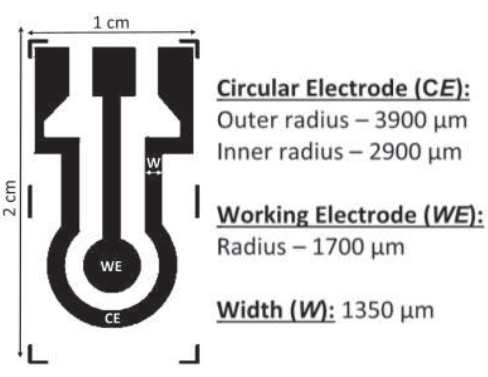

(a)

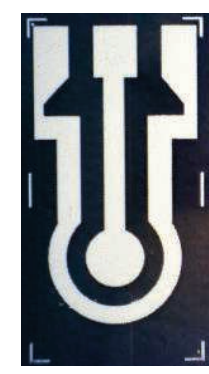

(b)
Fig. 1. (a) Schematic and (b) image of gravure printed electrochemical sensor.

salt $(\mathrm{KCl})$, a commonly used laboratory salt, were recorded using an LCR meter that was controlled by a custom built LabVIEW program. Different concentrations (100 pM, $100 \mathrm{nM}$, $100 \mu \mathrm{M}, 100 \mathrm{mM}$ ) of $\mathrm{KCl}$ was prepared by mixing $\mathrm{KCl}$ in deionized (DI) water. Initially, $120 \mu \mathrm{l}$ of the DI water is drop casted on the sensor to establish a reference signal. Then, $120 \mu \mathrm{l}$ of different concentrations of KCL was drop casted for obtaining EIS measurements.

\section{Results and Discussion}

The EIS response of the sensor was recorded at a frequency of $20 \mathrm{~Hz}$ and an excitation voltage of $100 \mathrm{mV}$. It was observed that the impedance decreased from $1329 \mathrm{k} \Omega$ to $207 \mathrm{k} \Omega$ to $183 \mathrm{k} \Omega$ to $68 \mathrm{k} \Omega$ to $1.2 \mathrm{k} \Omega$ as the concentration of the $\mathrm{KCl}$ solution increased from $\mathrm{DI}$ to $100 \mathrm{pM}$ to $100 \mathrm{nM}$ to $100 \mu \mathrm{M}$ to $100 \mathrm{mM}$, respectively ((Fig. 2(a)). This resulted in an impedance change of $84.4 \%, 86.2 \%$, $94.9 \%$ and $99.9 \%$ for the $100 \mathrm{pM}, 100 \mathrm{nM}$, $100 \mu \mathrm{M}$ and $100 \mathrm{mM} \mathrm{KCl}$ solutions, respectively, when compared to DI water ((Fig. 2(b)). The changes in the EIS response is due to variations in the ionic concentrations at the interface of sensor-analyte. The results demonstrate the capability of the printed sensor to detect trace levels of biochemicals at picomolar concentrations as well as different concentrations of the target molecules ranging from picomolar to millimolar concentrations.

\section{Conclusion}

In this work, a electrochemical sensor was fabricated by depositing Ag-NP ink on a flexible PET substrate using additive gravure printing process. The capability of the printed sensor was demonstrated by measuring its EIS response towards different concentrations of $\mathrm{KCl}$ solution. A decrease in impedance was observed from $1329 \mathrm{k} \Omega$ to $207 \mathrm{k} \Omega$ to $183 \mathrm{k} \Omega$ to $68 \mathrm{k} \Omega$ to $1.2 \mathrm{k} \Omega$ as the concentration of the $\mathrm{KCl}$ solution was increased from $\mathrm{DI}$ to $100 \mathrm{pM}$ to $100 \mathrm{nM}$ to $100 \mu \mathrm{M}$ to $100 \mathrm{mM}$, respectively, thus showing picomolar detection capability of the printed sensor. Further research includes studies to advance the detection capability of

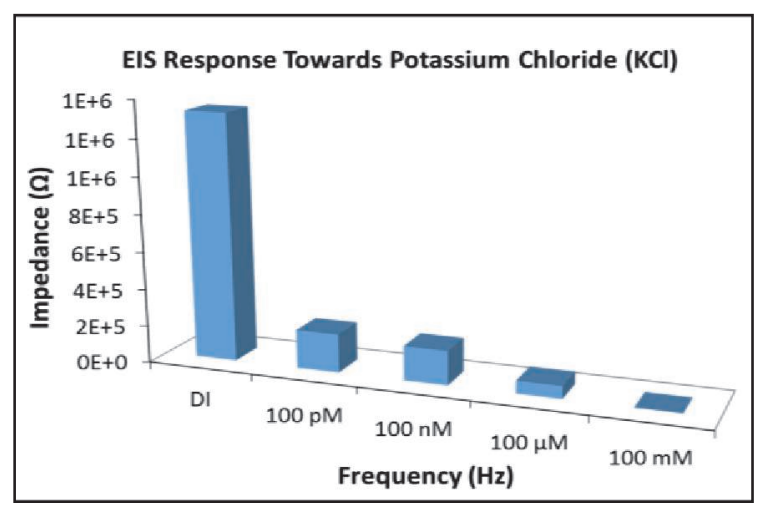

(a)

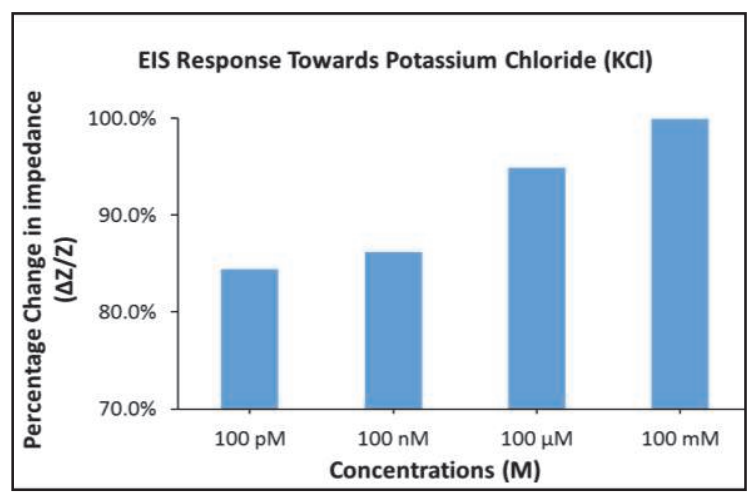

(b)

Fig. 2. (a) EIS response and (b) impedance change of sensor towards varying concentrations of $\mathrm{KCl}$.

the printed sensor towards a wider range of biochemical including toxic heavy metals (cadmium, arsenic and zinc) as well as sugars (glucose and sucrose). In addition, the use of sensing materials is also under investigation for improving the selectivity of the printed sensor.

\section{References}

[1] P. B. Luppa, C. Müller, A. Schlichtiger, H. Schlebusch, Point-of-care testing (POCT): current techniques and future perspectives, Trends Anal. Chem., 30, 887-898 (2011); doi: 10.1016/j.trac.2011.01.019.

[2] A. Ríos, M. Zougagh, M. Avila, Miniaturization through lab-on-a-chip: Utopia or reality for routine laboratories? A review, Analytica Chimica Acta, 740, 1-11 (2012); doi: 10.1016/j.aca.2012.06.024.

[3] A. Eshkeiti et al., Screen printing of multilayered hybrid printed circuit boards on different substrates, IEEE Trans. Compon. Packag. Manuf. Technol., 5, 415-421 (2015); doi: 10.1109/TCPMT.2015.2391012.

[4] D. Maddipatla et al. A novel flexographic printed strain gauge on paper platform, Proc. IEEE Sens., 1-4 (2015); doi: 10.1109/ICSENS.2015.7370606.

[5] B. B. Narakathu, A. Eshkeiti, A. S. G. Reddy, A. Moorthi, M. Z. Atashbar, A novel fully printed and flexible capacitive pressure sensor, Proc. IEEE Sens., 1935-1938 (2012); doi: 10.1109/ICSENS.2012.6411354. 